Supporting Information

\title{
Reactive Force Field-Based Molecular Dynamics Simulations on Thermal Stability of Trimesic Acid on Graphene: Implications for the Design of Supramolecular Networks
}

Daniela K. Jacquelín ${ }^{\mathrm{a}}$, Federico A. Soria ${ }^{\mathrm{b}}$, Patricia A. Paredes-Olivera ${ }^{\mathrm{b}}$, Eduardo M. Patrito ${ }^{\mathrm{a}^{*}}$

${ }^{a}$ Departamento de Fisicoquímica and ${ }^{b}$ Departamento de Química Teórica y Computacional. Instituto de Investigaciones en Físico Química de Córdoba (INFIQC). Facultad de Ciencias Químicas, Universidad Nacional de Córdoba, X5000HUA Córdoba, Argentina. 


\section{Density Functional Theory Calculations.}

DFT calculations were performed using the Quantum Espresso (QE) package. ${ }^{\text {S1 }}$ Norm-conserving ultrasoft pseudopotentials were employed for the atomic species. ${ }^{\text {S2 }}$ The PBE formulation was used for the exchange and correlation functional. ${ }^{\mathrm{S} 3}$ The electron wave functions were expanded in a plane-wave basis set up to a kinetic energy cutoff of 40 Ry (240 Ry for the density). The integration in the first Brillouin zone was performed with a $(4 \times 4 \times 1)$ Monkhorst-Pack mesh ${ }^{\mathrm{S} 4}$ for the structures shown in Figure S2 whereas for the molecules in Figure S1 and the structures in Figure S7, having large cell sizes, only one k point (gamma) was used for integration to obtain a good balance between the number of atoms and the computational burden. For the calculations involving the adsorption of TMA molecules (Figures S1 and S8) dispersive forces using Grimme's semiempirical DFT-D2 approach $^{\mathrm{S} 5}$ were included, as implemented in the PWscf code ${ }^{\mathrm{S} 1}$ of QE. In these calculations, a vacuum thickness of $12 \AA$ was introduced between the slabs. 
Table S1. Dimerization energies ( $\mathrm{kcal} / \mathrm{mol})$ of TMA, benzoic acid (BA), mercaptopropionic acid (MPA), acetic acid (AA), and formic acid (FA). The ab-initio values are compared with experimental values (when available) and with the values calculated with different ReaxFF potentials. BSSE stands for Basis Set Superposition Error corrections whereas vdW refers to the inclusion of van der Waals interactions.

\begin{tabular}{|c|c|c|c|}
\hline Dimer & $\Delta E$ & Method & Reference \\
\hline \multirow[t]{9}{*}{ FA-FA } & -18.50 & PBE/plane waves & This work \\
\hline & -16.6 & MP2/6-311G(d,p) & Tachikawa et al. ${ }^{\mathrm{S} 6}$ \\
\hline & -14.5 & MP2/6-311++G(d,p) & Tachikawa et al. ${ }^{\mathrm{S} 6}$ \\
\hline & -13.9 & $\operatorname{CCSD}(\mathrm{T}) / 6-311++\mathrm{G}(\mathrm{d}, \mathrm{p})$ & Tachikawa et al. ${ }^{\mathrm{S} 6}$ \\
\hline & -15.3 & MP2/aug-cc-pVTZ & Colominas et al. ${ }^{\mathrm{S7}}$ \\
\hline & -14.6 & B3LYP/6-311+G(2d,p) & Colominas et al. ${ }^{\mathrm{S} 7}$ \\
\hline & -15.55 & $\operatorname{CCSD}(\mathrm{T}) / \mathrm{CBS}$ & Kalescky et al. ${ }^{\mathrm{S} 8}$ \\
\hline & -14.32 & $\mathrm{CCSD}(\mathrm{T}) / \mathrm{CBS}$ with zero-point energy & Kalescky et al. ${ }^{\mathrm{S} 8}$ \\
\hline & -14.22 & Experiment & Kollipost et al. ${ }^{\mathrm{S} 9}$ \\
\hline \multirow[t]{6}{*}{ AA-AA } & -24.35 & B3LYP/6-31G(d,p) & Zhang et al. ${ }^{\mathrm{S} 10}$ \\
\hline & -20.14 & B3LYP/6-31G(d,p)/BSSE & Zhang et al. ${ }^{\mathrm{S} 10}$ \\
\hline & -19.21 & PBE/plane waves & This work \\
\hline & -18.7 & MP2/6-31G(d,p) & Rodríguez-Cuamatzi et al. ${ }^{\mathrm{S} 11}$ \\
\hline & -15.8 & MP2/aug-cc-pVTZ & Colominas et al. ${ }^{\mathrm{S}}$ \\
\hline & -15.1 & B3LYP/6-311+G(2d,p) & Colominas et al. ${ }^{\mathrm{S} 7}$ \\
\hline \multirow[t]{3}{*}{ BA-BA } & -19.3 & MP2/6-31G(d,p) & Rodríguez-Cuamatzi et al. ${ }^{\mathrm{S} 11}$ \\
\hline & -20.40 & B3LYP/6-31G(d,p) & Nath et al. ${ }^{\mathrm{S} 12}$ \\
\hline & -16.2 & Experiment & Allen et al. ${ }^{\mathrm{S} 13}$ \\
\hline MPA-MPA & -16.8 & PW91/6-31+G(d,p) & Carot et al. ${ }^{\mathrm{S} 14}$ \\
\hline \multirow[t]{9}{*}{ TMA-TMA } & -23.14 & B3LYP/6-31G(2d,2p)/vdW & Ibenskas et al. ${ }^{\mathrm{S} 15}$ \\
\hline & -18.78 & B3LYP/6-31G(2d,2p)/BSSE/vdW & Ibenskas et al. ${ }^{\mathrm{S} 15}$ \\
\hline & -19.4 & PBE/plane waves & This work \\
\hline & -20.02 & B3LYP/6-31G(d,p) & MacLeod et al. ${ }^{\mathrm{S} 16}$ \\
\hline & -16.36 & B3LYP/6-31G(d,p)/BSSE & MacLeod et al. ${ }^{\mathrm{S} 16}$ \\
\hline & -18.3 & ReaxFF / CHO & Chenoweth et al. ${ }^{\mathrm{S} 17}$ \\
\hline & -18.5 & ReaxFF / CHONSMgPNaCuCl_v2 & Monti et al. ${ }^{\mathrm{S} 18}$ \\
\hline & -9.4 & ReaxFF / CHON2017_weak & Zhang et al. ${ }^{\mathrm{S} 19}$ \\
\hline & -16.6 & $\begin{array}{l}\text { ReaxFF / CHO with true acetic acid } \\
\text { dissociation energy }\end{array}$ & Sengul et al. ${ }^{\mathrm{S} 20}$ \\
\hline
\end{tabular}




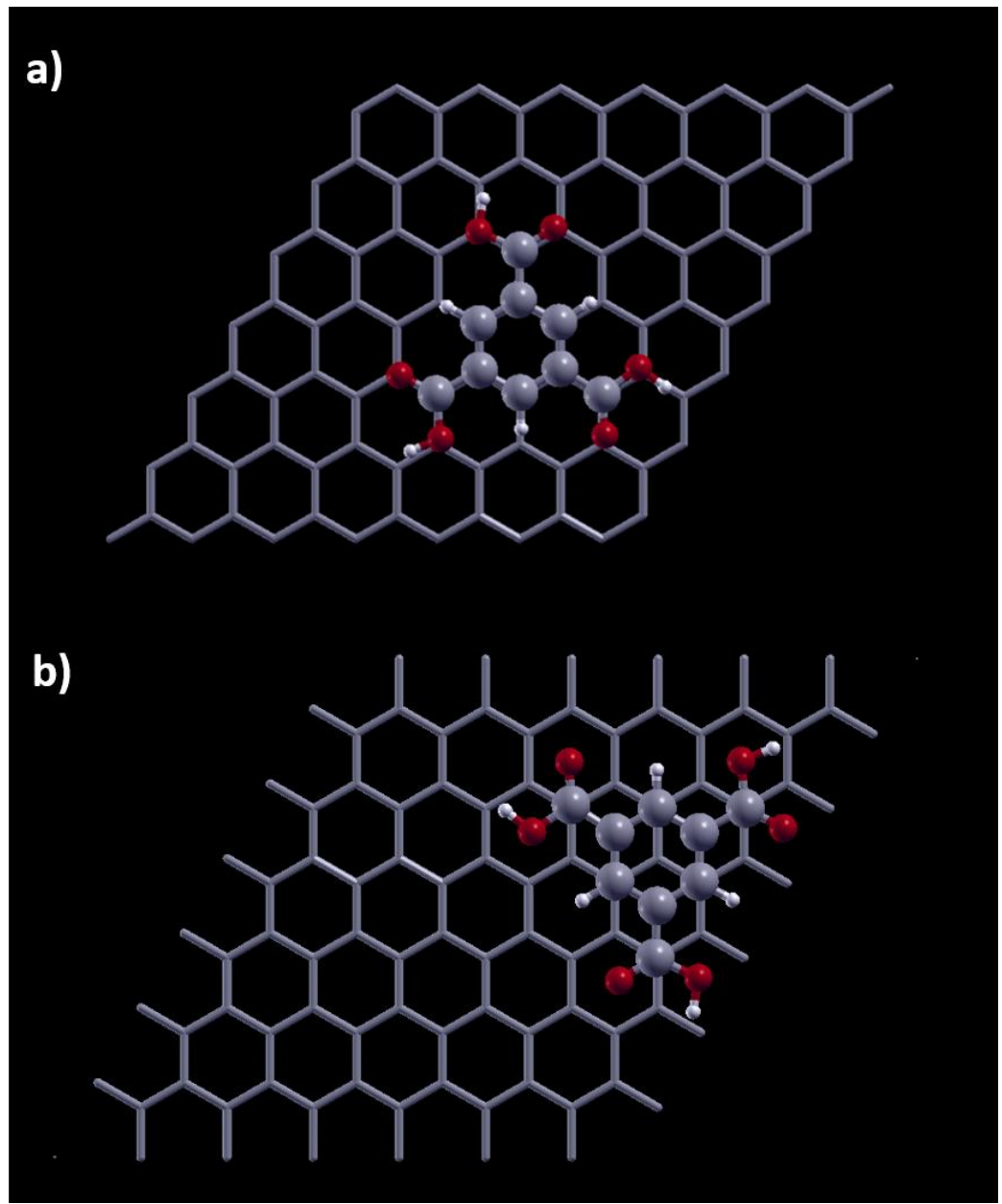

Figure S1. DFT optimized structures of a) formic acid, b) acetic acid and c) TMA dimers. The dotted lines indicate the hydrogen bonding. The following hydrogen bond lengths were obtained: $1.541 \AA, 1.533 \AA$ and $1.540 \AA$, respectively. The corresponding dimerization energies are: -18.50 $\mathrm{kcal} / \mathrm{mol},-19.21 \mathrm{kcal} / \mathrm{mol}-19.4 \mathrm{kcal} / \mathrm{mol}$, respectively. No dispersion forces were included in these calculations. 


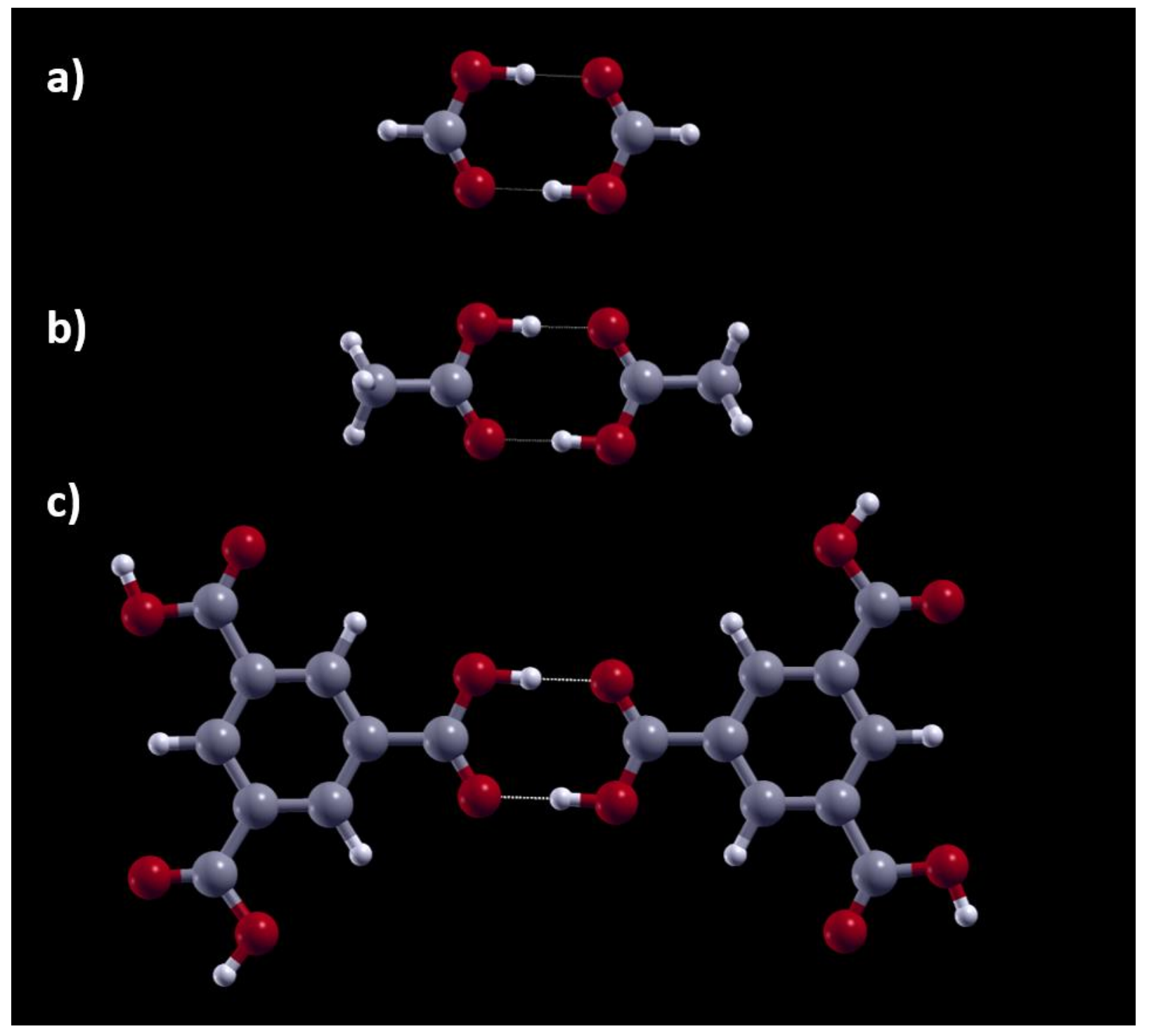

Figure S2. DFT equilibrium structures for a TMA molecule adsorbed on two different surface sites that were employed to calculate the adsorption energy $E_{\text {ads }}$ on graphene. a) All the $\mathrm{C}$ atoms of the benzene ring of TMA are on top of the $C$ atoms of graphene, $E_{a d s}=-20.4 \mathrm{kcal} / \mathrm{mol}$. b) The center of the benzene ring of TMA is on top of a $\mathrm{C}$ atom of graphene, $\mathrm{E}_{\text {ads }}=-23.3 \mathrm{kcal} / \mathrm{mol}$. Prior to the geometry optimizations, the graphene lattice was optimized and then kept fixed. We obtained a value of $1.444 \AA$ for the $\mathrm{C}-\mathrm{C}$ bond length of graphene. 

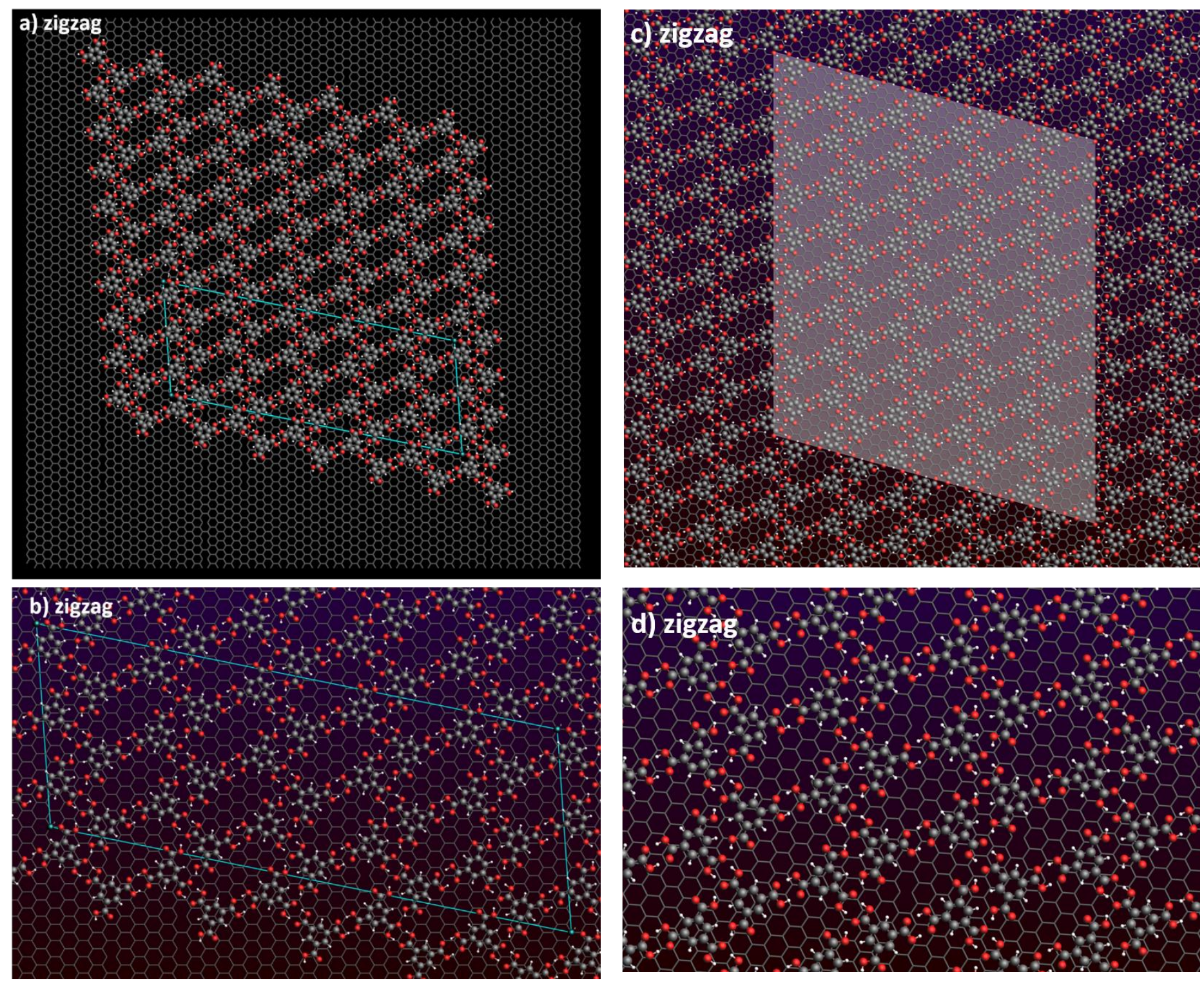

Figure S3. a) Equilibrium structure of an island of 140 TMA molecules with a zigzag structure. The equilibrium structure was obtained after a simulated annealing procedure in which the temperature in the NTV/MD simulations (during $250 \mathrm{ps)} \mathrm{was} \mathrm{decreased} \mathrm{from} 400 \mathrm{~K}$ to $1 \mathrm{~K}$ every $50 \mathrm{~K}$. Finally, a geometry optimization was performed. The unit cell which adequately reproduces the graphene and TMA periodicities is showed in the lower part of the TMA island. b) Detail of the unit cell deduced from the TMA island on graphene, having 30 TMA molecules. c) Final unit cell containing 90 TMA molecules, obtained by tripling the cell in the previous step. The structure shown corresponds to a geometry optimization performed after NVT/MD simulations at $10 \mathrm{~K}$ and $1 \mathrm{~K}$. d) detail of the zigzag structure to better appreciate the hydrogen bonding. 

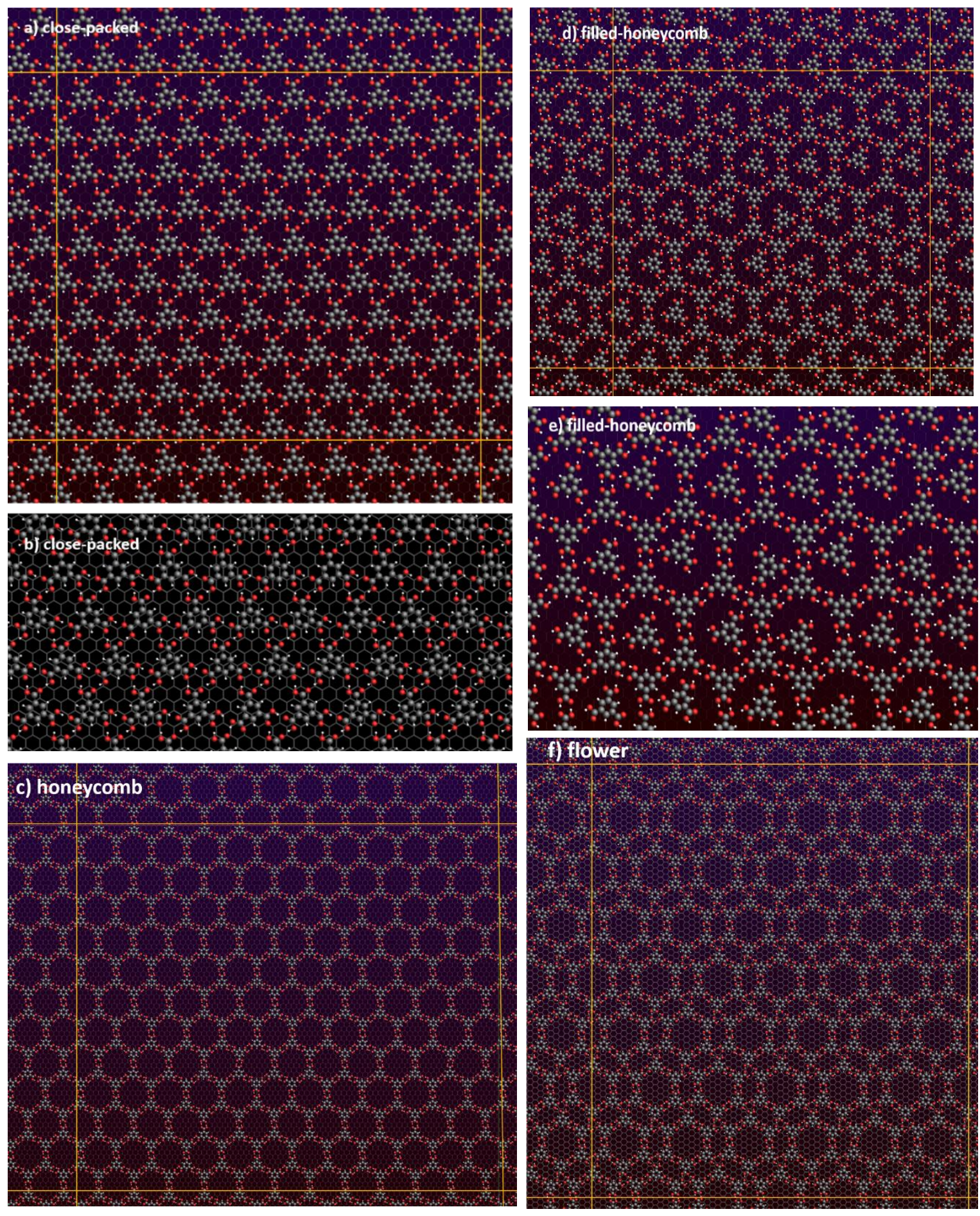

Figure S4. Unit cells employed in the NTV/MD simulations deduced following the procedure described for the previous Figure. a) Unit cell of close-packed structure having 100 TMA molecules. b) Detail of close-packed structure showing the trimeric hydrogen bonding among TMA molecules. c) Unit cell of honeycomb structure having 144 TMA molecules. For the structure we also used unit cells with 72 and 288 molecules. d) Unit cell of filled-honeycomb structure with 108 TMA molecules. e) Detail of filled honeycomb structure showing randomly located guest TMA molecules within the pores. f) Unit cell of flower structure with 288 TMA molecules. The dimensions of this cell are $156.0 \AA \times 180.2 \AA$ and contains 16416 atoms. 


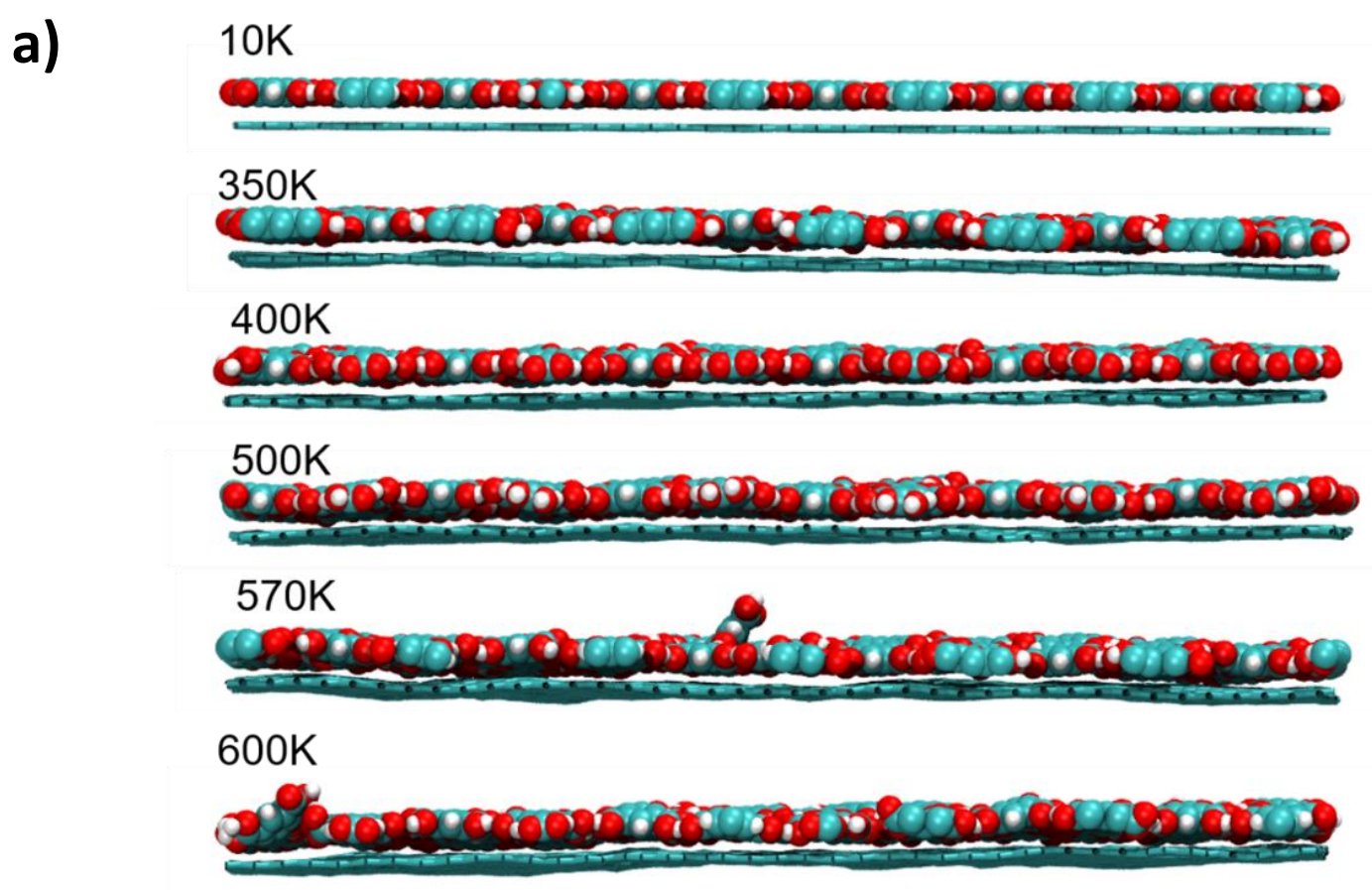

b)

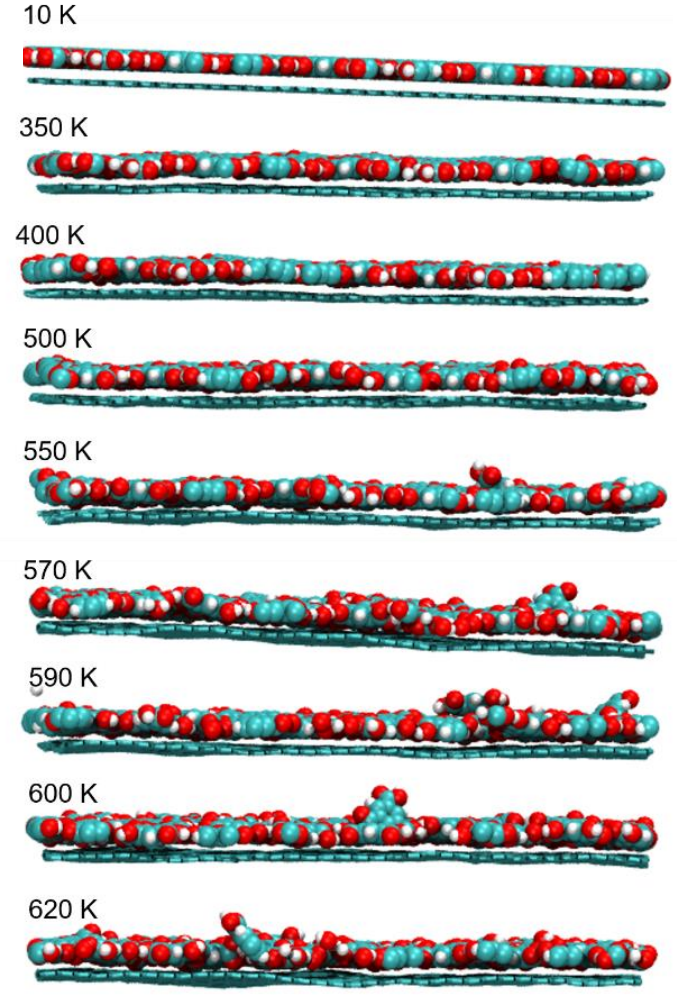

c)

$10 \mathrm{~K}$

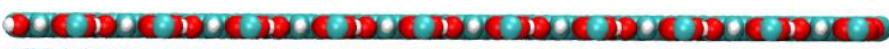
$350 \mathrm{~K}$

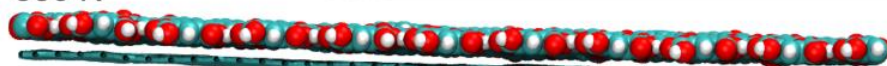
$400 \mathrm{~K}$

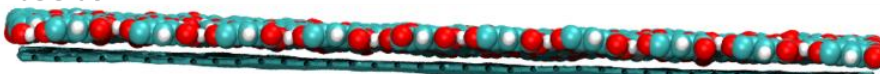
$500 \mathrm{~K}$

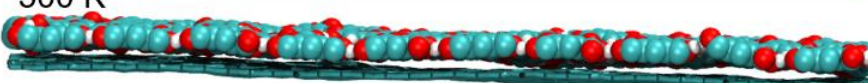
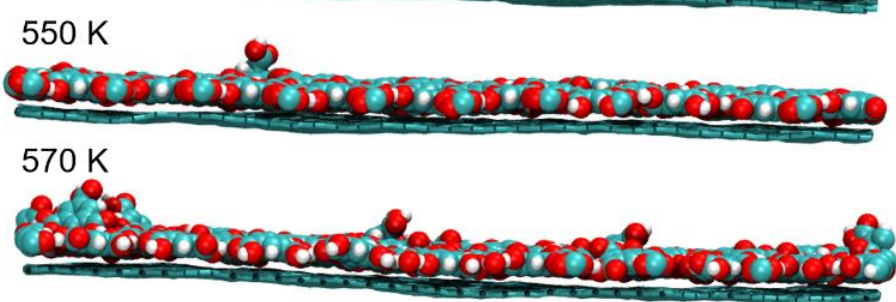

$579 \mathrm{~K}$

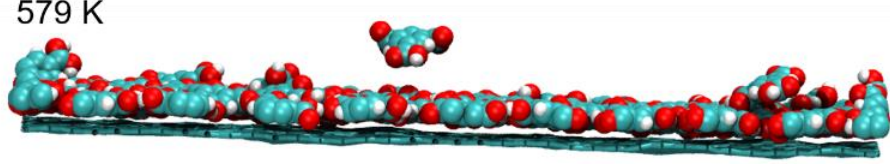

Figure S5. Snapshots of side views of NTV/MD simulations at different temperatures for the a) honeycomb, b) flower and c) close-packed structures. The out-of-plane twisting of molecules becomes more pronounced as the temperature increases. Partially desorbed molecules with one carboxylic group pointing away from the surface is observed before desorption. 


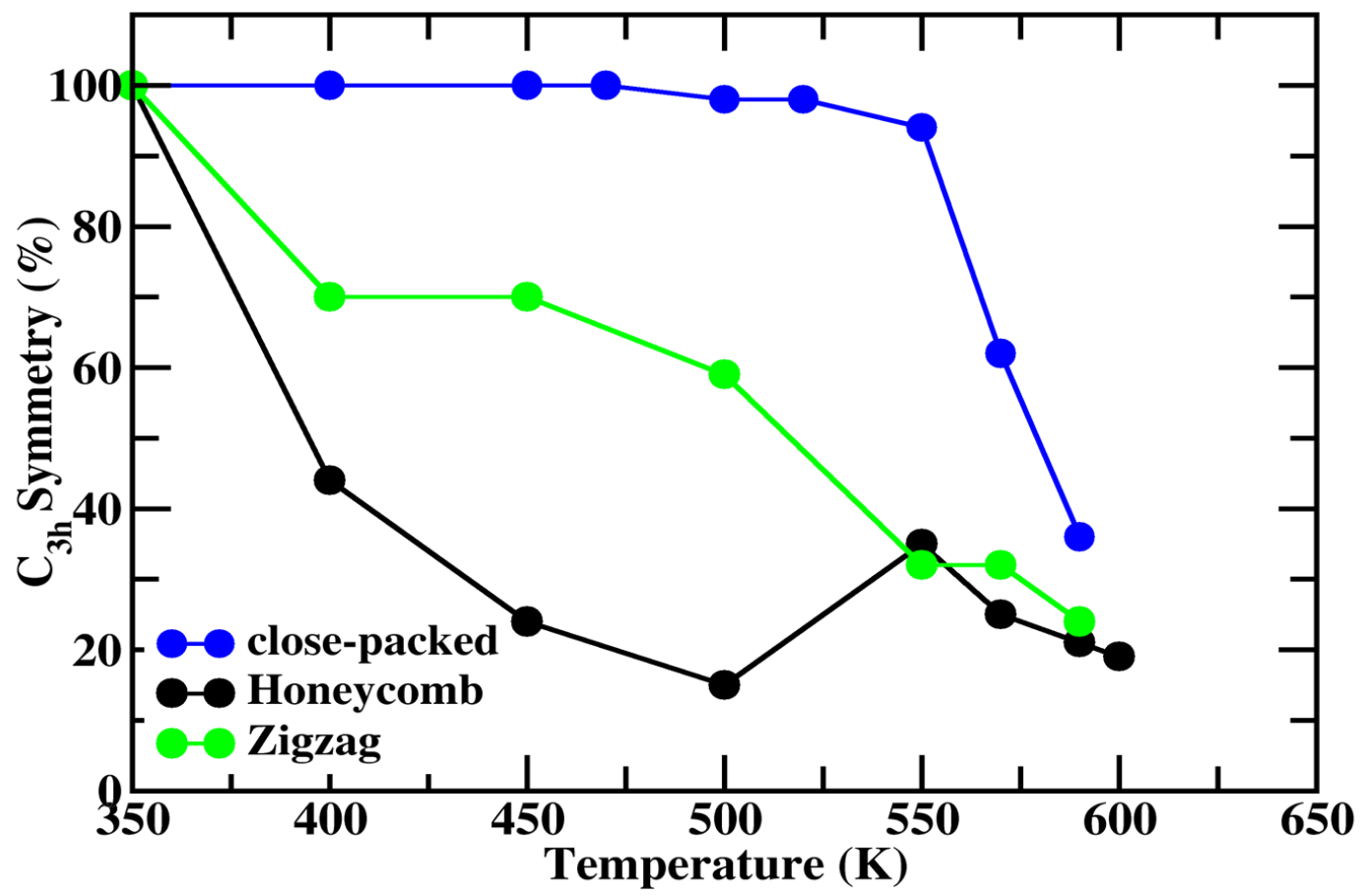

Figure S6. Percentage of molecules with $\mathrm{C}_{3 \mathrm{~h}}$ symmetry as a function of temperature for closepacked, honeycomb and zigzag structures. 

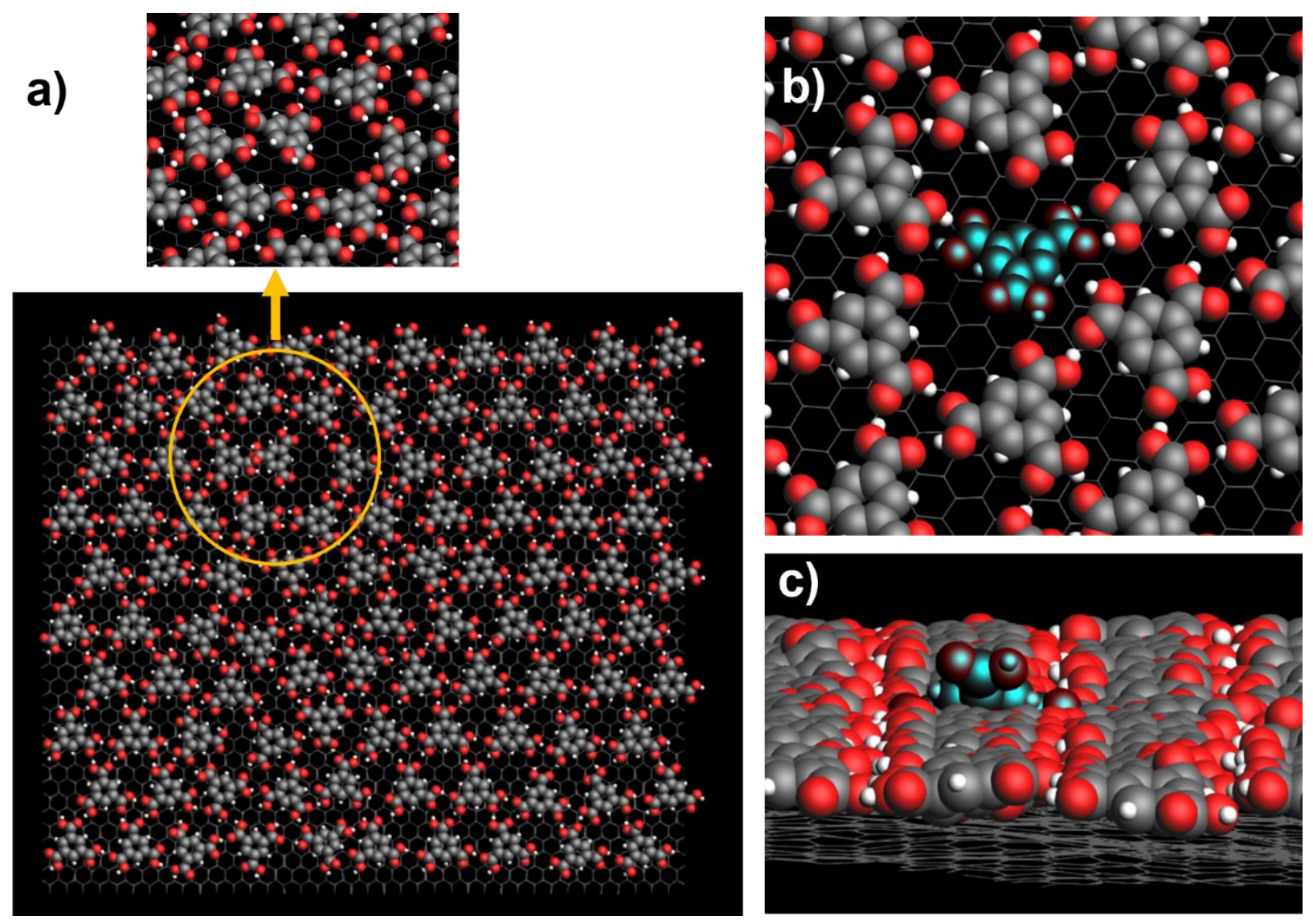

Figure S7. Initial steps of closed-pack structure decomposition at $500 \mathrm{~K}$ during fbMC simulation at $550 \mathrm{~K}$. a) The circled area shows 5 TMA molecules interconnected by dimeric hydrogen bonds forming a hexagonal pattern with another TMA molecule within the pore. b) The colored molecule has lost its trimeric interactions and has two carboxylic groups forming dimeric interactions with neighboring molecules. c) Because of steric interactions, the third carboxyl of the colored molecule points away from the surface. 

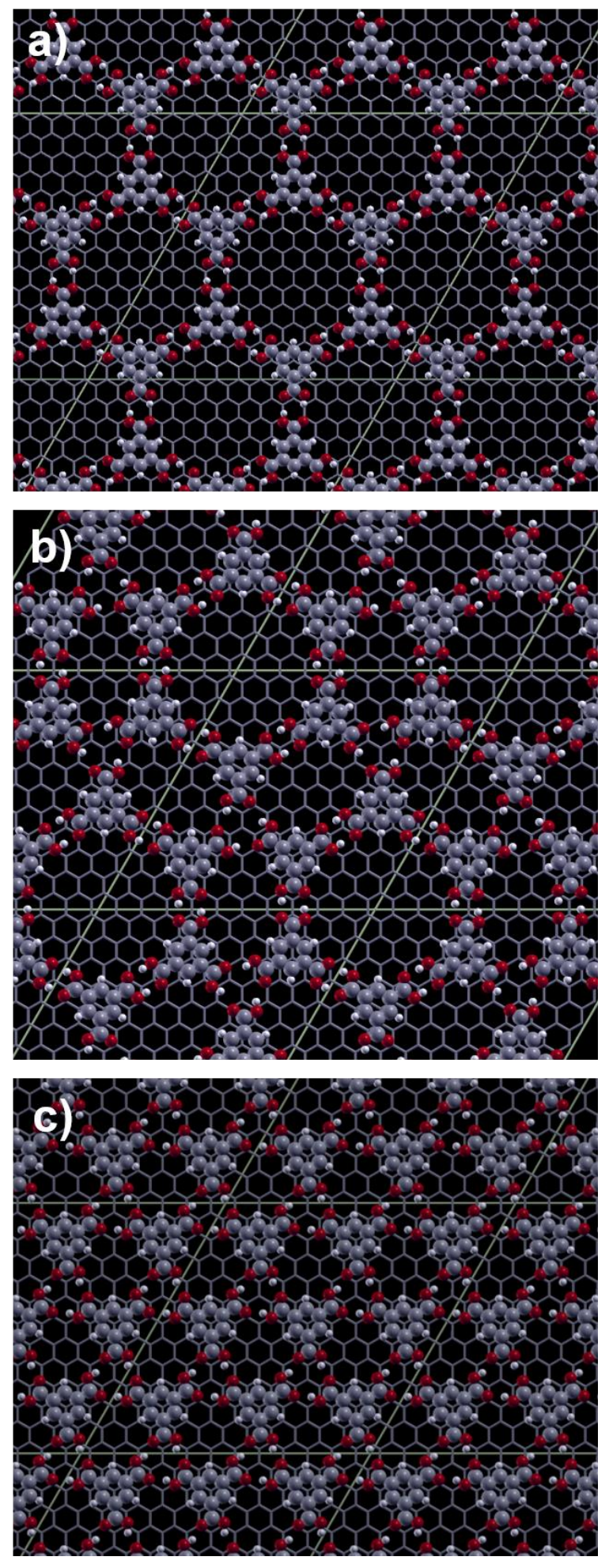

Figure S8. Equilibrium structures of different superstructures obtained from DFT calculations showing the unit cells employed. a) $14 \times 14$ graphene unit cell containing 8 TMA molecules with honeycomb structure b) $11 \times 11$ graphene unit cell containing 6 TMA molecules with flower structure. c) $12 \times 12$ graphene unit cell containing 9 TMA molecules with close-packed structure. 

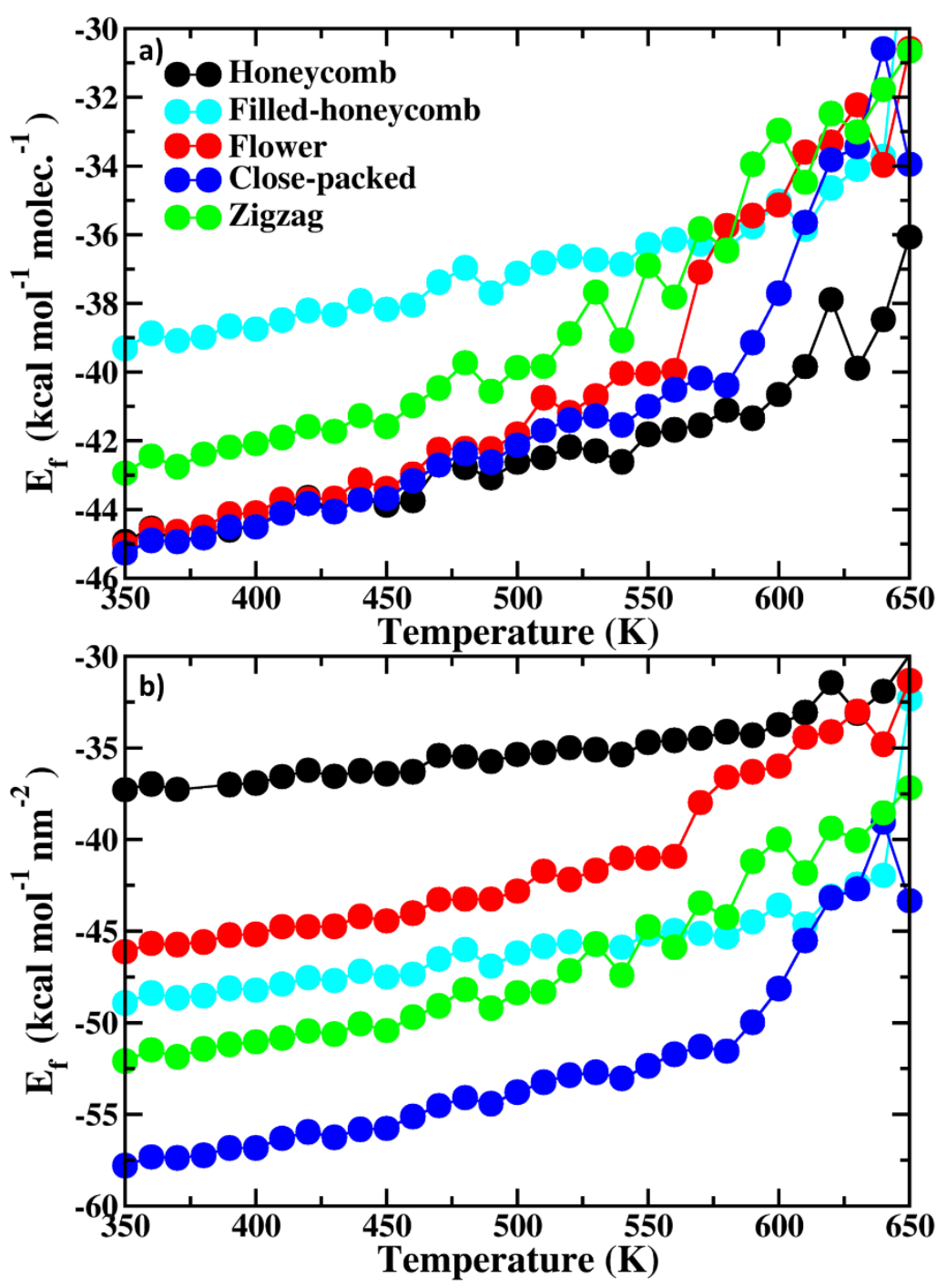

Figure S9. Formation energy normalized a) per TMA molecule and b) per surface area as a function of temperature for the indicated structures. The total energies of each structure were averaged over $250 \mathrm{ps}$ at each temperature in order to calculate the $\mathrm{E}_{\mathrm{f}}$ according to Eq. (3) in the manuscript. 


\section{References}

S1) Giannozzi, P.; Baseggio, O.; Bonfà, P.; Brunato, D.; Car, R.; Cavazzoni, C.; de Gironcoli, S.;

Delugas, P.; Ruffino, F. F.; Ferretti, A.; Marzari, N.; Timrov, I.; Urru, A.; Baroni, S.Quantum

ESPRESSO toward the Exascale. J. Chem. Phys. 2020, 152, 154105-154116.

S2) Vanderbilt, D. Soft self-consistent Pseudopotentials in a Generalized Eigenvalue Formalism. Phys. Rev. B 1990, 41, 7892-7895.

S3) Perdew, J. P.; Burke, K.; Ernzerhof, M. Generalized Gradient Approximation Made Simple. Phys. Rev. Lett. 1996, 77, 3865-3868.

S4) Monkhorst, H. J.; Pack, J. D. Special Points for Brillouin-Zone Integrations. Phys. Rev. B 1976, $13,5188-5192$.

S5) Grimme, S. Semiempirical GGA-type Density Functional Constructed with a Long-Range Dispersion Correction. J. Comput. Chem. 2006, 27, 1787-1799.

S6) Tachikawa, H. Proton Transfer vs Complex Formation Channels in Ionized Formic Acid Dimer: A Direct Ab Initio Molecular Dynamics Study. J. Phys. Chem. A 2020, 124, 3048-3054.

S7) Colominas, C.; Teixidó, J.; Cemelí, J.; Luque, F. J.; Orozco, M., Dimerization of Carboxylic Acids: Reliability of Theoretical Calculations and the Effect of Solvent. J. Phys. Chem. B 1998, 102, 2269-2276.

S8) Kalescky, R.; Kraka, E.; Cremer, D. Accurate Determination of the Binding Energy of the Formic Acid Dimer: the Importance of Geometry Relaxation. J. Chem. Phys. 2014, 140, 084315. S9) Kollipost, F.; Larsen, R. W.; Domanskaya, A. V.; Nörenberg, M.; Suhm, M. A. Communication: The Highest Frequency Hydrogen Bond Vibration and an Experimental Value for the Dissociation Energy of Formic Acid Dimer. J. Chem. Phys. 2012, 136, 151101.

S10) Zhang, M.; Chen, L.; Yang, H.; Ma, J. Theoretical Study of Acetic Acid Association Based on Hydrogen Bonding Mechanism. J. Phys. Chem. A 2017, 121, 4560-4568.

S11) Rodríguez-Cuamatzi, P.; Arillo-Flores, O. I.; Bernal-Uruchurtu, M. I.; Höpfl, H. Theoretical and Experimental Evaluation of Homo- and Heterodimeric Hydrogen-Bonded Motifs Containing Boronic Acids, Carboxylic Acids, and Carboxylate Anions: Application for the Generation of Highly Stable Hydrogen-Bonded Supramolecular Systems. Cryst. Growth Des. 2005, 5, 167-175. 
S12) Nath, K. G.; Ivasenko, O.; MacLeod, J. M.; Miwa, J. A.; Wuest, J. D.; Nanci, A.;

Perepichka, D. F.; Rosei, F. Crystal Engineering in Two Dimensions: An Approach to Molecular Nanopatterning. J. Phys. Chem. C 2007, 111, 16996-17007.

S13) Allen, G.; Watkinson, J. G.; Webb, K. H., An Infra-Red Study of the Association of Benzoic Acid in the Vapour Phase, and in Dilute Solution in non-Polar Solvents. Spectrochim. Acta 1966, $22,807-814$.

S14) Carot, M. L.; Macagno, V. A.; Paredes-Olivera, P.; Patrito, E. M. Structure of Mixed Carboxylic Acid Terminated Self-Assembled Monolayers: Experimental and Theoretical Investigation. J. Phys. Chem. C 2007, 111, 4294-4304.

S15) Ibenskas, A.; Šimėnas, M.; Tornau, E. E. Numerical Engineering of Molecular SelfAssemblies in a Binary System of Trimesic and Benzenetribenzoic Acids. J. Phys. Chem. C 2016, 120, 6669-6680.

S16) MacLeod, J. M.; Lipton-Duffin, J.; Fu, C.; Taerum, T.; Perepichka, D. F.; Rosei, F. A 2D Substitutional Solid Solution through Hydrogen Bonding of Molecular Building Blocks. ACS Nano 2017, 11, 8901-8909.

S17) Chenoweth, K.; van Duin, A. C. T.; Goddard, W. A. ReaxFF Reactive Force Field for Molecular Dynamics Simulations of Hydrocarbon Oxidation. J. Phys. Chem. A 2008, 112, 10401053.

S18) Monti, S.; Corozzi, A.; Fristrup, P.; Joshi, K. L.; Shin, Y. K.; Oelschlaeger, P.; van Duin, A. C. T.; Barone, V. Exploring the Conformational and Reactive Dynamics of Biomolecules in Solution Using an Extended Version of the Glycine Reactive Force Field. Phys. Chem. Chem. Phys. 2013, 15, 15062-15077.

S19) Zhang, W.; van Duin, A. C. T. Improvement of the Reaxff Description for Functionalized Hydrocarbon/Water Weak Interactions in the Condensed Phase. J. Phys. Chem. B 2018, 122, 4083-4092.

S20) Sengul, M. Y.; Randall, C. A.; van Duin, A. C. T. ReaxFF Molecular Dynamics Simulation of Intermolecular Structure Formation in Acetic Acid-Water Mixtures at Elevated Temperatures and Pressures. J. Chem. Phys. 2018, 148, 164506. 